\title{
A Study on the Performance of Dye Sensitized Solar Cells Using Extract from Wrightia tinctoria R.Br. as Photosensitizers
}

\author{
ANEESIYA K. RAJAN ${ }^{1}$ and L. CINDRELLA ${ }^{1,2}$ \\ 1.-Fuel Cell, Energy Materials and Physical Chemistry Lab, Department of Chemistry, National \\ Institute of Technology, Tiruchirappalli 620015, India. 2.—e-mail: cind@nitt.edu
}

In this study, eco-friendly natural dye sensitizers were extracted from the dried leaves of Wrightia tinctoria R.Br. (commonly known as "Pala indigo" or "Dyer's oleander") by cold methanolic and soxhlet extraction and used in dye sensitized solar cells (DSSC). The acidification of the extracted pigments was carried out using $0.1 \mathrm{~N} \mathrm{HCl}$. The absorption characteristics were studied by UV-visible spectroscopy, and the functional groups were identified by Fourier transform infrared spectroscopy. DSSCs constructed using these sensitizers were evaluated in terms of current density-voltage characteristics and electrochemical response. The DSSC fabricated with natural dye extracted by cold methanol exhibited maximum power conversion efficiency of $0.19 \%$. The efficiency of the acidified cold methanolic extract-based DSSC was $0.06 \%$.

Key words: Dye sensitized solar cell, Wrightia tinctoria, chlorophyll, indirubin, $\mathrm{J}-\mathrm{V}$ characteristics

\section{INTRODUCTION}

Photovoltaic technology is a promising alternative to fossil fuel-based conventional energy systems, of which the dye sensitized solar cell (DSSC) has captivated researcher intrest in recent years. ${ }^{1}$ In an attempt to replace ruthenium complexes, the most commonly used dye sensitizers in DSSC, low-cost and widely available natural sensitizers extracted from fruits, leaves, and flowers have been successfully studied for use as sensitizers in DSSCs. ${ }^{2}$ DSSCs are photo-electrochemical cells typically composed of a dye-embedded mesoporous metal oxide film, a tri-iodide redox system, and a counter electrode made up of conducting materials with suitable bandgap. ${ }^{3}$ These components must be optimized to produce efficient and more stable devices. A highest power conversion efficiency of $13 \%$ has been reported currently for DSSC sensitized with ruthenium-based dyes. ${ }^{4}$ As far as natural dyes are concerned, their method of extraction and purification are cost-effective and non-tedious in

(Received May 24, 2019; accepted September 27, 2019; published online October 11, 2019) comparison to other organic dyes. The byproducts of complex organic reactions are either toxic or perilous to the environment, and hence the possibilities for the implementation of natural dyes are bright.

In this study, we report the DSSC performance by using the natural dye sensitizers extracted from the leaves of a widely available medicinal plant, Wrightia tinctoria R.Br. The plant is also known as Pala indigo or Dyer's oleander. ${ }^{5}$ This is a flowering plant found throughout India, Southeast Asia, Indonesia, and Australia. All parts of the plant are sources of indigo-yielding glucoside. The current study is based on extract from the dried leaves by following two different types of extraction methods, namely, soxhlet extraction and simple cold methanolic extraction. Wrightia tinctoria leaf extract has many medicinal applications, especially in the field of antimicrobial activity against $E$. coli and Staphylococcus aureus. ${ }^{6}$ Investigations on this plant suggested the presence of indigo, tryptanthrin, phytosteroids, several tri-terpenoids, ${ }^{7}$ terpenes such as wrightial, ${ }^{8}$ anthranilic acid, indirubin, isatin, and flavonoid glycoside rutin in the plant leaves. ${ }^{9}$ The fresh leaves of the plant are completely devoid of indirubin, while it is found to be an artifact 
formed only during the drying process after harvesting the leaves. ${ }^{10}$ The chemical transformation of indole metabolites is caused by the intact hydrolytic enzyme systems and by auto-oxidation of indoxyl glycosides, i.e., by the condensation of free indoxyl and isatin. The schematic representation of the probable sequence of the formation of indigo, isatin, indiruin, and tryptanthrin is shown in Fig. 1.

After treatment with $0.1 \mathrm{~N} \mathrm{HCl}$, the concentration of indirubin increases due to the hydrolysis of indoxyl glycoside. ${ }^{11}$ The presence of indigotin can also be observed in fresh leaves and dried leaves, but are complementary to indirubin. A seasonal pigment variation is observed in this plant, and the highest concentration of indirubin has been observed from August to November. So the leaves were harvested in the above period from Ernakulam district, Kerala, India. ${ }^{11}$ Through this work, the possibility to apply $W$. tinctoria leaf extracts as sensitizers in DSSC is proposed.

1)

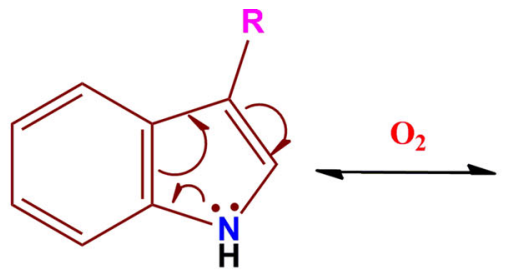<smiles>[R]C1=C2C=CC=CC2N=C1</smiles><smiles>CC[13CH][13CH]</smiles>

(a)

2)

(a)<smiles>Oc1c[nH]c2ccccc12</smiles>

(c)<smiles>O=C1Nc2ccc(O)cc2C1=O</smiles>

(d)

3)

(c) $+(d)$

Isatin

4)

Anthranilic acid $+(\mathrm{d}) \longrightarrow$ Tryptanthrin

Where,<smiles>COC1O[C@H](CO)[C@@H](O)[C@H](O)[C@H]1O</smiles>

$R=$ beta-D-glucosyl<smiles>O=C1/C(=C2\Nc3ccccc3C2=O)Nc2ccccc21</smiles>

Indigotin<smiles>O=C1c2ccccc2-n2c1nc1ccccc1c2=O</smiles>

Tryptanthrin<smiles>O=C1Nc2ccccc2/C1=C1/Cc2ccccc2C1=O</smiles>

Isatin

Fig. 1. Schematic representation of the formation of the active constituents in dried leaves of Wrightia tinctoria. 


\section{EXPERIMENTAL SECTION}

\section{Extraction of Dyes}

The collected fresh leaves of $W$. tinctoria were washed with Milli-Q water, dried for 15 days and preserved under vacuum. Two different types of extraction techniques have been employed, namely cold methanolic extraction and soxhlet extraction. The cold methanolic extract was prepared by soaking $0.5 \mathrm{~g}$ of the powdered leaves in $50 \mathrm{~mL}$ of methanol, stirred on a magnetic stirrer for $2 \mathrm{~h}$ and left undisturbed in the dark for $24 \mathrm{~h}$. Then the resultant solution was filtered and collected to obtain pure natural dye solutions. Acidified cold methanolic extracts were also prepared with $0.1 \mathrm{~N}$ $\mathrm{HCl}$. The soxhlet extraction using methanol has been carried out to obtain the extract from dried leaves. For this, $2 \mathrm{~g}$ of powdered leaves were treated with $100 \mathrm{~mL}$ of freshly distilled methanol and kept for $5 \mathrm{~h}$ at a temperature of $65{ }^{\circ} \mathrm{C}$. The residual solution was collected, centrifuged and filtered using Whatman No 40 filter paper. The acidified solution of the extracts was prepared by using $0.1 \mathrm{~N}$ $\mathrm{HCl}$ solution. The $\mathrm{pH}$ of the acidified extracts was maintained in between 2.4 and 2.8. All the acidified extracts were usually stable with a deactivation half-time of more than a year. ${ }^{12}$ The cold methanolic extract, acidified cold methanolic extract, soxhlet extract, and acidified soxhlet extracts were called WTM, WTMH, WTS, and WTSH, respectively.

\section{Fabrication of Dye Sensitized Solar Cell}

Conductive glass plates used to make the working and counter electrodes were cleaned by standard methods using sodium dodecyl sulfate solution, Milli-Q water, acetone, and isopropyl alcohol sequentially for $15 \mathrm{~min}$ each. The working electrode was fabricated with $\mathrm{TiO}_{2}$ paste (Dyesol (R) 18 NR-T) deposited onto a fluorine-doped tin oxide (FTO) glass plate (sheet resistance $\sim 13 \Omega \mathrm{sq}^{-1}$ ) in $0.25 \mathrm{~cm}^{2}$ area. The electrode was calcined at $500^{\circ} \mathrm{C}$ for $30 \mathrm{~min}$. When the temperature of the electrode reached $\sim 80^{\circ} \mathrm{C}$, the electrodes were soaked in the respective dye solutions for $24 \mathrm{~h}$ in the dark. The counter-electrodes were prepared by using platinum paste, air-dried and calcined at $450^{\circ} \mathrm{C}$ for $15 \mathrm{~min}$. A redox electrolyte comprising $0.5 \mathrm{M}$ 4-tert-butyl pyridine (TBP), $0.05 \mathrm{M}$ iodine $\left(I_{2}\right)$ and $0.5 \mathrm{M}$ lithium iodide (LiI) in 3-methoxypropionitrile has been used.

\section{Measurements and Characterizations}

UV-visible absorption spectra of the samples were taken by using a Shimadzu UV-2600 spectrophotometer. A Thermo Scientific (Nicolet iS5) spectrometer with attenuated total reflectance accessory was used to identify the functional groups and fingerprint regions of the prepared extracts. A CHI608B electrochemical analyzer was used for the cyclic voltammetric studies. The photovoltaic performance has been evaluated under simulated light source (AM $1.5 \mathrm{G}, 100 \mathrm{~mW} \mathrm{~cm}^{-2}$ ) using Oriel LCS-100 solar simulator. The interface charge transfer resistance of the fabricated DSSCs was determined by electrochemical impedance spectroscopy with an $\mathrm{AC}$ amplitude of $5 \mathrm{~mW}$ in the frequency range of $0.05-10,000 \mathrm{~Hz}$.

\section{RESULTS AND DISCUSSION}

\section{UV-Visible Absorption Spectra of Dye Solutions}

The UV-visible absorption spectra of the samples (Fig. 2) reveal the presence of chlorophyll pigments in the extracts by the absorption peaks in the range of 400-665 nm. Two major absorption bands observed at about 665-653 and 418-410 nm, viz "red" (Q) and "blue" (Soret) bands, are characteristic of chlorophylls. They exhibit an extended $\pi$-delocalization at the edge of the porphyrin ring system. ${ }^{13}$ The acidification of the extracts resulted in the formation of two $\mathrm{Mg}^{2+}$ voided pigments from chlorophyll "a", viz pheophytin-a and pheophoride-a, and this was supported by the shift in the absorption spectra. The peak at $410 \mathrm{~nm}$ (blue part) for nonacidified extracts intensified and shifted to $418 \mathrm{~nm}$, and the peak at $664 \mathrm{~nm}$ (red part) was shifted to $653 \mathrm{~nm}$ due to the formation of pheopigments. ${ }^{14}$

For all the extracts, a strong far-UV absorption band has been observed. Because of the strong absorption at around $653 \mathrm{~nm}$, it can act as a good sensitizer for DSSCs. These natural dyes are the source of a variety of chemical compounds and show various shoulder peaks corresponding to indirubin and trypatanthrin, which usually appear at $\sim 400$ and $\sim 550 \mathrm{~nm}$, respectively. The absorption in these regions was observed for all the extracts, and also WTMH and WTSH showed an enhancement in the

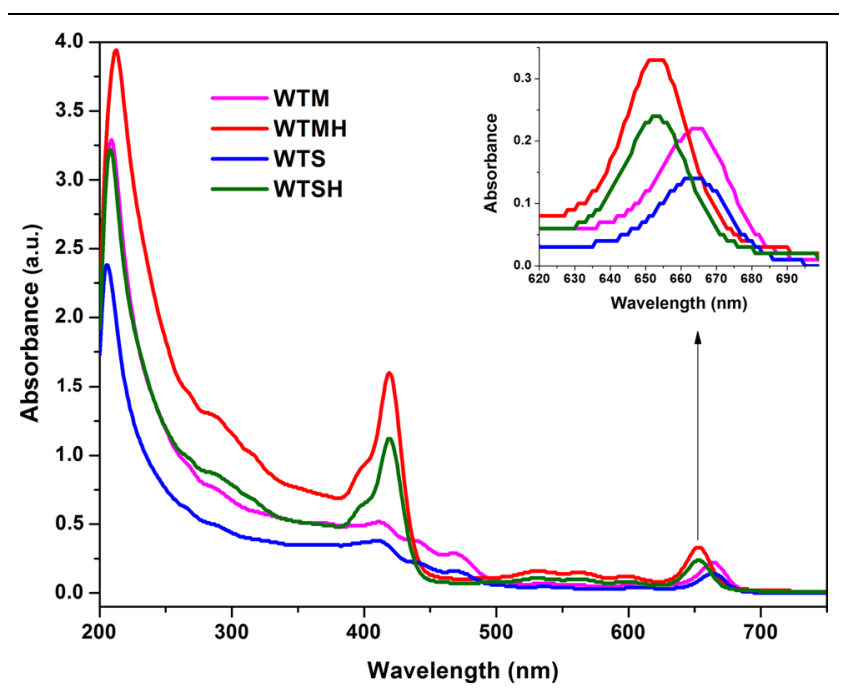

Fig. 2. UV-visible absorption spectra of cold methanolic extract (WTM), acidified cold methanolic extract (WTMH), soxhlet extract (WTS), and acidified soxhlet extract (WTSH). Absorbance in the range, $620-680 \mathrm{~nm}$ is shown as the inset. 
absorption intensity at around $550 \mathrm{~nm}$ due to the presence of higher amount of indirubin in the acidified extracts.

\section{FT-IR Spectra of Dye Solutions}

Figure 3 represents the IR spectrum of the extract from dried leaves. From the spectrum, the functional groups present in the liquid extracts could be identified.

The -OH stretching vibrations of glycosidic groups present in the chemical constituents of the extracts are characterized by the peaks at 3322 , 3319,3314 , and $3323 \mathrm{~cm}^{-1} \cdot 15$ The bands appearing at 2944,2943 and $2832 \mathrm{~cm}^{-1}$ represent the alkane $-\mathrm{CH}$ stretching vibrations. The presence of $>\mathrm{C}=\mathrm{O}$ stretching vibrational modes is evidenced by the peaks at $1667 \mathrm{~cm}^{-1} \cdot{ }^{16}$ At $1448 \mathrm{~cm}^{-1}$, the scissoring vibrational modes of $-\mathrm{CH}_{3}$ vibrations can be observed. ${ }^{17}$ The peaks at 1113,1114 and $1028 \mathrm{~cm}^{-1}$ reflect the stretching vibrations of $-\mathrm{C}-\mathrm{N}$ amines and the peak at $607 \mathrm{~cm}^{-1}$ agree with the $-\mathrm{C}-\mathrm{H}$ out-of-plane bending vibrations. ${ }^{18}$

\section{Electrochemical Properties}

The redox properties of the natural dye extracts were studied by cyclic voltammetry (CV) and are represented in Fig. 4a. The screen-printed carbon electrodes with a modified graphene working electrode (4 mm diameter), carbon counter electrode and $\mathrm{Ag}-\mathrm{AgCl}$ reference electrode were used for $\mathrm{CV}$. The dye solutions were drop-casted on the modified graphene electrode and air-dried. Cyclic voltammetry was performed in the voltage range from -1.2 to $1.2 \mathrm{~V}$ with a scan rate of $50 \mathrm{mV} \mathrm{s}^{-1}$. An inert electrolyte of $0.1 \mathrm{M}$ tetrabutyl ammonium hexafluoro phosphate was used. The relationship, $E_{\text {HOMO }}=-\left(4.4+E_{\text {ox, onset }}\right)(\mathrm{eV})$ has been used to calculate the HOMO and LUMO levels of the dyes,

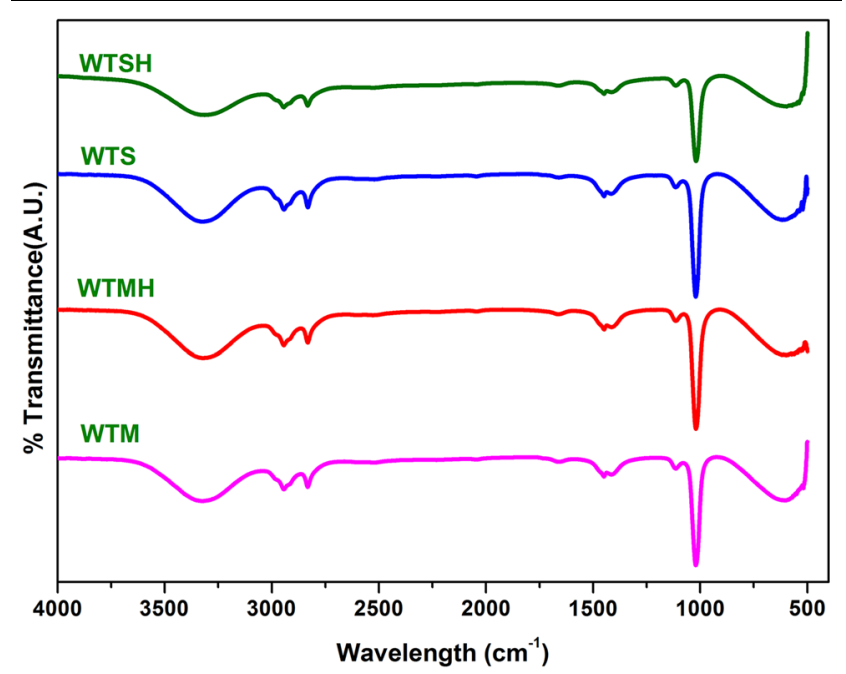

Fig. 3. FT-IR spectra of cold methanolic extract (WTM), acidified cold methanolic extract (WTMH), soxhlet extract (WTS), and acidified soxhlet extract (WTSH). inferring $4.4 \mathrm{eV}$ difference from the vacuum level. The equation, $E_{\mathrm{LUMO}}=E_{\mathrm{HOMO}}+E_{\mathrm{g}}^{\mathrm{opt}}(\mathrm{eV})$ has been used for calculating the LUMO values, where $E_{\mathrm{g}}^{\mathrm{opt}}$ is the optical bandgap of the dyes obtained from the Tauc plots (Fig. 4b). ${ }^{19}$ Table 1 summarizes the obtained electrochemical data. The energy difference between the LUMO and the conduction band of the semiconductor should be more than $0.2 \mathrm{eV}$ for efficient transfer of photoexcited electrons. Similarly $0.2-0.3 \mathrm{eV}$ energy difference is needed for the effective electron regeneration through $I^{-} / I_{3}^{-}$redox couple within the electrolyte. ${ }^{20}$ The sensitizers, WTM and WTS satisfy the later criterion for the effective electron transfer and the remaining two lack the later property.

\section{Photovoltaic Performances of DSSCs}

The photovoltaic parameters of the fabricated DSSCs are evaluated through current-voltage characteristics represented in Fig. 5, and the parameters obtained are summarized in Table 2. The photovoltaic conversion efficiency of the device can be calculated by using the following relationship:

$$
\boldsymbol{\eta}=\boldsymbol{V}_{\mathrm{oc}} \times \boldsymbol{J}_{\mathrm{sc}} \times \frac{f f}{\boldsymbol{P}(\boldsymbol{i n})}
$$

where $f f$ is the fill factor;

$$
\boldsymbol{f f}=\frac{\boldsymbol{P}_{\max }}{\boldsymbol{J}_{\mathrm{sc}} \times \boldsymbol{V}_{\mathrm{oc}}}
$$

$\boldsymbol{J}_{\mathrm{sc}}$ and $\boldsymbol{V}_{\mathrm{oc}}$ are the short-circuit current density and open-circuit voltage, respectively.

The highest $\boldsymbol{J}_{\mathrm{sc}}$ values of 0.19 and $0.17 \mathrm{~mA} \mathrm{~cm}{ }^{-2}$ were observed for non-acidified plant extracts. This is in contrast to the reported studies, where acidified extracts enhanced the conversion efficiency of the DSSC. ${ }^{21}$ The highest open-circuit voltage of $510 \mathrm{mV}$ was observed for WTM. The highest photovoltaic conversion efficiency of $0.19 \%$ was obtained for WTM, and the least efficiency of $0.06 \%$ was observed for WTMH.

All the extracts show a good range of fill factor values $(0.65-0.69)$. The acidification of the extracts resulted in the formation of two $\mathrm{Mg}^{2+}$ voided pigments from chlorophyll "a", viz pheophytin-a and pheophoride-a. The absence of $\mathrm{Mg}^{2+}$ in chlorophylls affects the electron transfer in the chlorine ring system. Changing the central metal changes the absorption spectra of the chlorophylls, most likely in a way to be less effective at energy transfer through the Forster resonance mechanism. Chlorophylls use a magnesium ion at the center of a porphyrin ring to absorb light energy and excite an electron within the system to a higher energy level, thereby enabling the magnesium ion to act as an antenna in chlorophylls. These mechanisms are absent in pheopigments which affects the electron injection process to the conduction band of $\mathrm{TiO}_{2}$ in such systems. The photovoltaic performance of DSSC depends upon the initial 

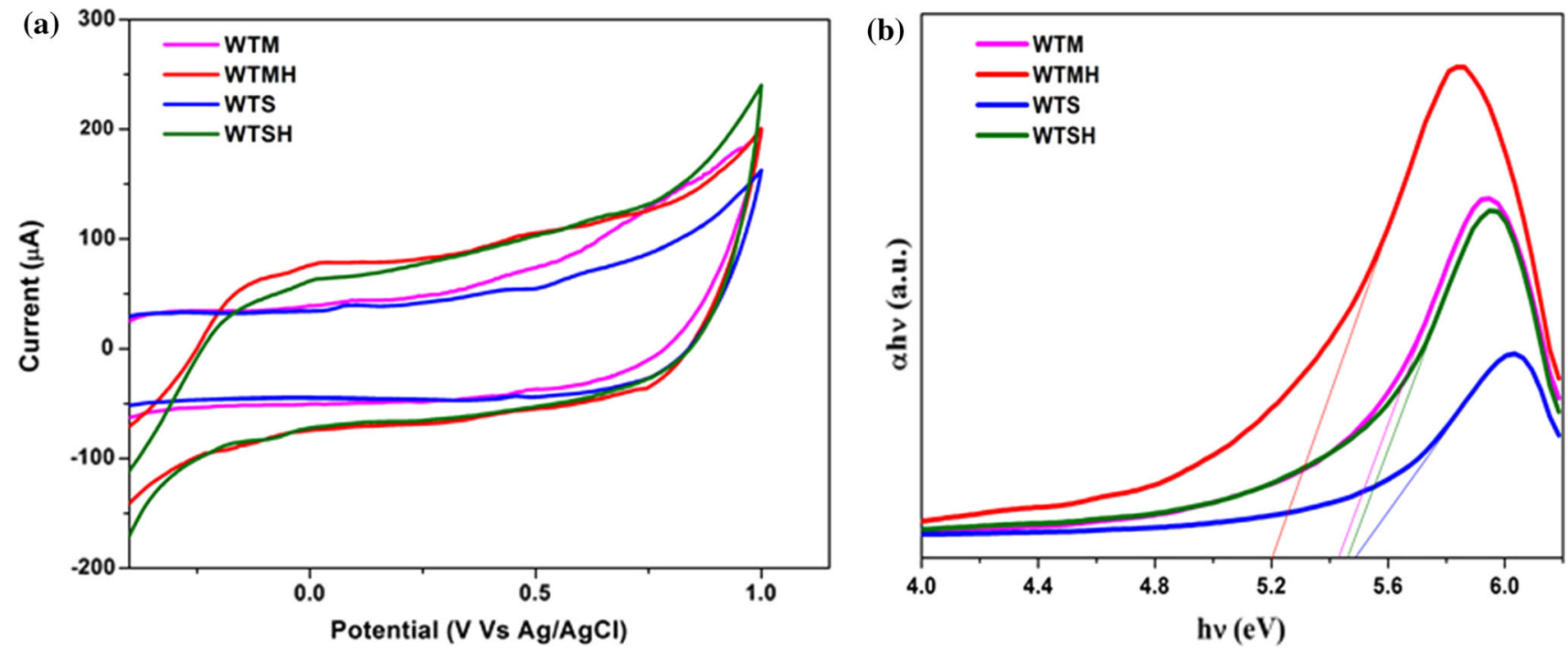

Fig. 4. Cyclic voltammograms (a) and Tauc-plots (b) of cold methanolic extract (WTM), acidified cold methanolic extract (WTMH), soxhlet extract (WTS) and acidified soxhlet extract (WTSH).

Table 1. Electrochemical and optical properties of the natural dyes extracted by cold methanol (WTM), acidified cold methanol (WTMH), soxhlet by methanol (WTS) and soxhlet by acidified methanol (WTSH)

\begin{tabular}{|c|c|c|c|c|}
\hline Sensitizer & $E_{\text {ox, }}$ onset $(\mathrm{V})$ & $E_{\text {HOMo }}(\mathbf{e V})$ & $E_{\text {LUMo }}(\mathbf{e V})$ & $E_{\mathrm{g}}^{\text {opt }}(\mathbf{e V})$ \\
\hline WTM & 0.549 & -4.949 & 0.483 & 3.741 \\
\hline WTMH & 0.269 & -4.669 & 0.861 & 4.076 \\
\hline WTS & 0.492 & -4.892 & 0.307 & 3.600 \\
\hline WTSH & 0.162 & -4.562 & 0.899 & 3.660 \\
\hline
\end{tabular}

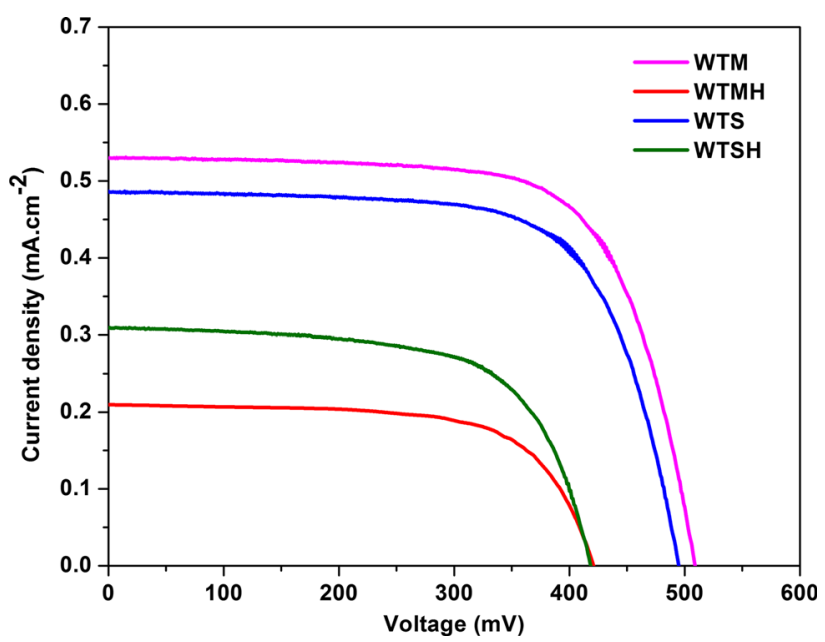

Fig. 5. Current density-voltage curves for DSSCs fabricated with cold methanolic extract (WTM), acidified cold methanolic extract (WTMH), soxhlet extract (WTS), and acidified soxhlet extract (WTSH).

number of photogenerated electrons. The $\mathrm{Mg}^{2+}$ ions which act as antenna molecules, enhance the light absorption, effective electron excitation, and transfer in non-acidified extract-based DSSCs. From the observations, it can also be inferred that the pigments in the acidified extracts have a negative effect on the
Table 2. Photovoltaic performance parameters of DSSCs fabricated with cold methanolic extract (WTM), acidified cold methanolic extract (WTMH), soxhlet extract (WTS), and acidified soxhlet extract (WTSH)

\begin{tabular}{|c|c|c|c|c|}
\hline Sensitizer & $J_{s c}\left(\mathbf{m A ~ c m} \mathbf{c m}^{-2}\right)$ & $V_{\text {oc }}(\mathbf{m V})$ & $f f$ & $\eta(\%)$ \\
\hline WTM & 0.53 & 510 & 0.69 & 0.19 \\
\hline WTMH & 0.21 & 422 & 0.66 & 0.06 \\
\hline WTS & 0.49 & 495 & 0.69 & 0.17 \\
\hline WTSH & 0.31 & 419 & 0.65 & 0.08 \\
\hline
\end{tabular}

performance of DSSC due to concealing and agglomeration effects that are not suitable for light absorption and effective anchoring of the dye in spite of the highly intense absorption properties. ${ }^{22,23}$ Some unfavorable intermolecular interactions are also found between various pigments which lead to dye aggregation and finally to diminution of photovoltaic performance.

\section{Electrochemical Impedance Spectroscopic Studies}

Interface charge transfer properties of the fabricated DSSCs have been investigated through 

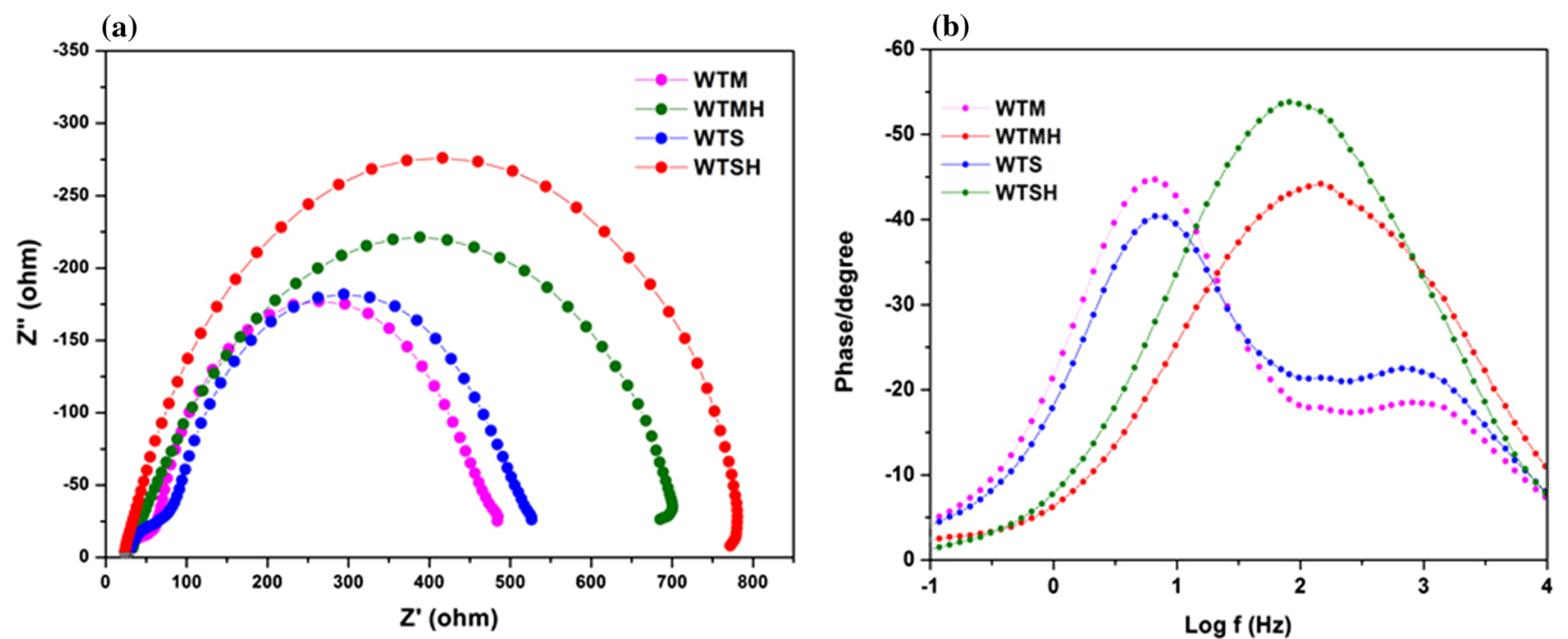

Fig. 6. Nyquist plots (a) and Bode plots (b) for fabricated devices with cold methanolic extract (WTM), acidified cold methanolic extract (WTMH), soxhlet extract (WTS) and acidified soxhlet extract (WTSH).

electrochemical impedance spectroscopy (EIS) under simulated light (AM 1.5). This is a tool used to determine the internal resistance and interfacial reactions of the excited electrons in the DSSCs. Typical Nyquist plot of EIS comprises of three semicircles. The charge transfer resistance $\left(R_{1}\right)$ at the Pt-electrode/electrolyte interface was earmarked by the small semicircle observed in the high-frequency region. ${ }^{24}$ The large semicircle seen at middle frequency region corresponds to the electron recombination resistance $\left(R_{2}\right)$ at $\mathrm{TiO}_{2} /$ dye/electrolyte interface. ${ }^{25}$ The small semicircle observed at frequencies less than $0.1 \mathrm{~Hz}$ is associated with Warburg diffusion of the $I^{-} / I_{3}^{-}$redox couple within the electrolyte. The Nyquist plots for the fabricated DSSCs are shown in Fig. 6a. The $R_{1}$ values are in the order, WTS $>$ WTM. The $R_{2}$ values followed the order, WTM $<$ WTS $<$ WTSH $<$ WTMH. $R_{1}$ was not identified in the case of DSSCs fabricated with the acidified extracts due to the longer lifetime of the respective process. ${ }^{26}$ The lower $R_{2}$ value of WTM based DSSC facilitates the electron transfer across $\mathrm{TiO}_{2}$ /dye/electrolyte interface which is reflected in the efficiency of the device. The device formed of WTMH showed a high value for $R_{2}$ which indicated a high charge transfer resistance across the interfaces leading to poor efficiency of $0.06 \%$. The electron recombination lifetime $\left(\tau_{\mathrm{e}}\right)$ in the devices was calculated using the Bode-plot of EIS measurements and the relationship, $\tau_{\mathrm{e}}=1 /\left(2 \pi f_{\max }\right)$, where $f_{\max }$ is the peak frequency of the intermediate frequency arc in the Bode plot as shown in Fig. $6 \mathrm{~b}$. The calculated $f_{\max }$ values and electron lifetime values are tabulated in Table 3. The electron lifetime values are 69.95, $18.26,69.90$ and $23.56 \mathrm{~ms}$ for the devices fabricated with WTM, WTMH, WTS, and WTSH, respectively. The increased electron lifetime in a WTM-based
Table 3. Electrochemical parameters derived from Bode plots of EIS measurements for DSSCs fabricated with cold methanolic extract (WTM), acidified cold methanolic extract (WTMH), soxhlet extract (WTS) and acidified soxhlet extract (WTSH)

\begin{tabular}{lcc}
\hline Sensitizer & $\boldsymbol{f}_{\max }(\mathbf{H z})$ & \\
WTM & 2.27 & 69.95 \\
WTMH & 8.71 & 18.26 \\
WTS & 2.28 & 69.90 \\
WTSH & 6.75 & 23.56 \\
\hline
\end{tabular}

device prevents the back reaction of injected photoexcited electrons with the redox mediator. ${ }^{27}$ This reduced recombination rate increases the photocurrent density and photo-voltage of the device, and hence the efficiency also. The photovoltaic conversion efficiency of the fabricated devices are further supported by the EIS results.

\section{CONCLUSION}

In summary, natural dye sensitizers were extracted from the plant Wrightia tinctoria and used in dye sensitized solar cells. The maximum photovoltaic conversion efficiency of $0.19 \%$ was obtained for DSSC fabricated by using the cold methanolic extract, whereas the device fabricated with dyes WTS, WTMH and WTSH showed $0.17 \%$, $0.06 \%$, and $0.08 \%$ efficiency, respectively. From the results it could be inferred that the method of extraction and solvent $\mathrm{pH}$ have greater influence on the device performance. The UV-visible spectra revealed the presence of chlorophylls, pheopigments, indigo, indirubin and other similar plant pigments in the extract. A suitable method of extraction of indigo pigments and its 
implementation in DSSCs will direct the incorporation of materials with suitable optoelectronic properties to exploit the wide absorption spectrum, and the same is in progress.

\section{ACKNOWLEDGMENTS}

The authors gratefully acknowledge MHRD, Government of India, for the research fellowship and lab facilities.

\section{DATA AVAILABILITY}

The raw/processed data required to reproduce these findings cannot be shared at this time as the data also forms part of an ongoing study.

\section{REFERENCES}

1. W. Ghann, H. Kang, T. Sheikh, S. Yadav, T. Chavez-Gil, F. Nesbitt, and J. Uddin, Sci. Rep. 7, 41470 (2017).

2. W. Maiaugree, S. Lowpa, M. Towannang, P. Rutphonsan, A. Tangtrakarn, S. Pimanpang, P. Maiaugree, N. Ratchapolthavisin, W. Sang-Aroon, and W. Jarernboon, Sci. Rep. 5, 15230 (2015).

3. A. Orona-Navar, I. Aguilar-Hernández, A. Cerdán-Pasarán, T. López-Luke, M. Rodríguez-Delgado, D. Cárdenas-Chávez, E. Cepeda-Pérez, and N. Ornelas-Soto, Algal Res. 26, 15 (2017).

4. S. Mathew, A. Yella, P. Gao, R. Humphry-Baker, B.F. Curchod, N. Ashari-Astani, I. Tavernelli, U. Rothlisberger, M.K. Nazeeruddin, and M. Grätzel, Nat. Chem. 6, 242 (2014).

5. J.P.F. Deleuze, History and description of the Royal Museum of Natural History (Paris: A. Royer, 1823).

6. C. Jolly and N.R. Mechery, Comparative pharmacognostical, Indian. J. Pharm. Sci. 51, 58 (1996).

7. Y. Chadha, The Wealth of India-Raw Materials (Council of Scientific and Industrial Research, New Delhi 1976),https:// www.niscair.res.in/activitiesandservices/products/wealth-o f-indiaFolder2010.pdf. Accessed 5 June 2010.

8. P. Ramchandra, M. Basheermiya, G. Krupadanam, and G. Srimannarayana, J. Nat. Prod. 56, 1811 (1993).
9. S. Sathyanarayanan, P. Selvam, J. Asha, R. George, K. Revikumar, and J. Neyts, Int. J. Chem. Sci. 7, 1 (2009).

10. M. Khyade and N. Vaikos, Int J Pharm Bio Sci 2, 176 (2011).

11. A. Muruganandam, S. Bhattacharya, and S. Ghosal, Indian J. Chem. 39B, 125 (2000).

12. S. Sathyajothi, R. Jayavel, and A.C. Dhanemozhi, Mater. Today: Proc. 4, 668-676 (2017).

13. S.M. Milenković, J.B. Zvezdanović, T.D. Anđelković, and D.Z. Marković, Adv. Technol. 1, 16-24 (2012).

14. J.R. Moed and G.M. Hallegraeff, Int. Rev. Hydrobiol. 63, 787 (1978).

15. H.-G. Jang, B.-G. Heo, Y.S. Park, J. Namiesnik, D. Barasch, E. Katrich, K. Vearasilp, S. Trakhtenberg, and S. Gorinstein, Appl. Biochem. Biotechnol. 167, 1986 (2012).

16. K. Hemalatha, S. Karthick, C.J. Raj, N.-Y. Hong, S.-K. Kim, and H.-J. Kim, Spectrochim. Acta, Part A. 96, 305 (2012).

17. S. Martini, C. D'Addario, C. Bonechi, G. Leone, A. Tognazzi, M. Consumi, A. Magnani, and C. Rossi, J. Photochem. Photobiol., B 101, 355 (2010).

18. N. Chanayath, S. Lhieochaiphant, and S. Phutrakul, Chiang Mai Univ. Sci. Fac. J. 1, 149-160 (2002).

19. A.K. Rajan and L. Cindrella, Opt. Mater. 88, 39 (2019).

20. N.C.D. Nath, H.J. Lee, W.-Y. Choi, and J.-J. Lee, Electrochim. Acta 109, 39 (2013).

21. W.A. Ayalew and D.W. Ayele, Jour. Sci.: Adv. Mater. Devices 1,488 (2016).

22. N. Kumara, P. Ekanayake, A. Lim, M. Iskandar, and L.C. Ming, J. Sol. Energy Eng. 135, 031014 (2013).

23. N. Kumara, P. Ekanayake, A. Lim, L.Y.C. Liew, M. Iskandar, L.C. Ming, and G. Senadeera, J. Alloys Compd. 581, 186 (2013).

24. C.-P. Hsu, K.-M. Lee, J.T.-W. Huang, C.-Y. Lin, C.-H. Lee, L.-P. Wang, S.-Y. Tsai, and K.-C. Ho, Electrochim. Acta 53, 7514 (2008).

25. S.-M. Wang, L. Liu, W.-L. Chen, E.-B. Wang, and Z.-M. Su, Dalton Trans. 42, 2691 (2013).

26. F. Bella, S. Galliano, M. Falco, G. Viscardi, C. Barolo, M. Grätzel, and C. Gerbaldi, Chem. Sci. 7, 4880 (2016).

27. E.N. Kumar, R. Jose, P. Archana, C. Vijila, M. Yusoff, and S. Ramakrishna, Energy Environ. Sci. 5, 5401 (2012).

Publisher's Note Springer Nature remains neutral with regard to jurisdictional claims in published maps and institutional affiliations. 